\title{
AVALIAÇÃO DO PROCESSO DE OBTENÇÃO DE LEITE EM PÓ PELO PROCESSO DE SECAGEM EM SPRAY DRYER
}

\author{
M. BALKE ${ }^{1}$, J. KILIAN ${ }^{2}$, C. STEFFENS ${ }^{2}$, M. B. A. SOARES ${ }^{2}$, J. STEFFENS ${ }^{2}$ \\ ${ }^{1}$ Instituto Federal Rio Grande do Sul Campus Erechim \\ ${ }^{2}$ Universidade Regional Integrada do Alto Uruguai e das Missões, Departamento \\ de Engenharia de Alimentos \\ marlova.balke@erechim.ifrs.edu.br
}

\begin{abstract}
RESUMO - O objetivo deste trabalho foi à obtenção de leite ovino em pó por meio de secagem por Spray Dryer, utilizando planejamento $2^{3}$ (DCCR), onde as variáveis independentes avaliadas foram: pressão (0,9-1,9 bar), vazão de alimentação $(3,0-5,4 \mathrm{~L} / \mathrm{h})$ e temperatura $\left(143,2-186,8{ }^{\circ} \mathrm{C}\right)$, as respostas avaliadas foram: conversão de produto, tempo de processamento e umidade do pó. A melhor conversão de produto na etapa de secagem foi no ensaio 6 com pressão de 1,8 bar; $3,5 \mathrm{~L} / \mathrm{h}$ de vazão e $170{ }^{\circ} \mathrm{C}$ de temperatura de alimentação. Já para o menor tempo de processamento (1h e $10 \mathrm{~min}$ ), foi obtido no ensaio 4 para 1,8 bar; $4,9 \mathrm{~L} / \mathrm{h}$ e $150^{\circ} \mathrm{C}$. Pode-se verificar que as variáveis conversão de produto e tempo de processamento ficaram dentro da mesma faixa de pressão, no entanto para a conversão de produto necessitou-se menor vazão e maior temperatura, ao contrário do verificado para o tempo de processamento. Com relação à umidade o ensaio 4 que teve maior conversão de produto foi o que obteve menor teor de umidade dentre todos os experimentos do planejamento $(1,22 \%)$.
\end{abstract}

\section{INTRODUÇÃO}

Nos últimos anos tem ocorrido uma expansão na ovinocultura no Brasil, o qual é o maior produtor da América do Sul, a produção de leite ovino tem sido vista como uma alternativa sustentável, de baixo investimento inicial e de fácil adoção pela mão de obra familiar, podendo melhorar a qualidade de vida dos pequenos produtores rurais.

O leite de ovelha difere das demais espécies especialmente pela riqueza dos constituintes (gordura, proteína, lactose e sais minerais) os quais são muito superiores em relação ao leite de vaca, porém a maior parte do leite de ovelha obtido é transformada em queijo e em menor escala em 
iogurte, estes produtos apresentam elevado valor comercial (ASSENAT 1991).

Segundo Tormen (2011), não existe dados de comercialização no Brasil do leite fluido de ovelha, isso se deve ao alto valor pago pelo litro, baixo volume de produção em relação ao bovino e à sua baixa durabilidade mesmo em temperaturas de refrigeração. A produção de leite em pó de ovelha é uma alternativa para agregar valor a está matéria prima tão nobre e com valores nutricionais tão diferenciados, a técnica de secagem utilizada industrialmente é a técnica de aspersão "Spray dryer".

Produtos em pó apresentam uma baixa umidade, o que dificulta ou até impede o crescimento de microrganismos e as reações físico-químicas responsáveis por sua deterioração. Além disso, a produção de leite em pó apresenta como vantagem uma maior facilidade de transporte, armazenamento e manuseio do produto final, seja ele para o consumo na forma direta, ou como ingrediente na elaboração de outros produtos alimentícios.

Diante do acima exposto este trabalho teve como objetivo principal a obtenção do leite em pó de ovelha, através do processo de secagem por spray drying e avaliação do teor de umidade dos produtos obtidos.

\section{MATERIAL E MÉTODOS}

\subsection{Matéria-prima}

Como matéria prima foi utilizado o leite de ovelha das raças Lacaune e Frisona Milchschaf doada pela Cabanha Chapecó localizada no município de Chapecó Santa Catarina.

Após a ordenha mecânica o leite ficou armazenado em resfriador do tipo granel em temperatura em torno de $4^{\circ} \mathrm{C}$, após esta etapa o leite foi transportado em recipientes plásticos e em caixas térmicas até o laboratórios de tecnologia de leite e derivados da URI campus Erechim.

\subsection{Preparo das Amostras}

Inicialmente, o leite foi pasteurizado no laboratório de tecnologia de leites e derivados da URI campus Erechim, a técnica empregada foi a pasteurização do tipo lenta $\left(63^{\circ} \mathrm{C}\right.$ por 30 minutos $)$.

Em seguida o Leite foi concentrado em rota evaporador da marca Quimis® modelo Q344B por 
30 minutos em temperatura de $60^{\circ} \mathrm{C}, 62 \mathrm{rpm}$ e 20 pol $\mathrm{Hg}$ de pressão.

\subsection{Secagem em Spray Dryer}

A secagem foi realizada em um secador laboratorial com sistema de atomização em bicos mini spray dryer - Lab Plant, modelo SD-05 (Huddersfield, U.K.), com bico injetor de 0,5 mm de diâmetro, fluxo de ar de $73 \mathrm{~m} 3 / \mathrm{h}$, disponível no Laboratório de Fenômenos de Transporte, na URI campus Erechim.

Os ensaios foram realizados de acordo com um delineamento composto central rotacional $2^{3}$ completo. As variáveis independentes foram: temperatura do ar de secagem, vazão mássica de alimentação e pressão. As respostas avaliadas no planejamento foram conversão de produto (Equação 1), tempo de processamento e umidade do produto obtido. A Tabela 1 apresenta os valores das variáveis independentes codificadas e os ensaios realizados para o planejamento experimental.

$$
\text { Conversão }(\%)=\frac{m_{i}-m_{f}}{m_{i}} \quad \text { Equação (1) }
$$

Onde: $\quad m_{i}=$ Massa do leite fluido $(\mathrm{Kg}) ; \quad m_{f}=$ Massa do leite em pó $(\mathrm{Kg})$;

Tabela 1: Variáveis independentes codificadas.

\begin{tabular}{lccccc}
\hline Variáveis & $-1,68$ & -1 & 0 & +1 & $+1,68$ \\
Temperatura $\left({ }^{0} \mathrm{C}\right)$ & 143 & 150 & 160 & 170 & 187 \\
Vazão $(\mathrm{L} / \mathrm{h})$ & 3,0 & 3,5 & 4,2 & 4,9 & 5,4 \\
Pressão (bar) & 0,9 & 1,2 & 1,6 & 1,8 & 1,9 \\
\hline
\end{tabular}

\subsection{Determinação da Umidade}

A determinação da umidade do leite em pó foi determinada gravimetricamente em estufa de recirculação (Fanem - 320 - SE) a $105^{\circ} \mathrm{C}$ por aproximadamente $4 \mathrm{~h}$ e/ou até peso constante, segundo metodologia descrita por BRASIL (2005), as análises foram realizadas em triplicata. 


\section{RESULTADOS E DISCUSSÃO}

Para melhor avaliação do processo de secagem a ferramenta utilizada foi à metodologia de planejamento experimental DCCR (Tabela 2). A Tabela 2 mostra que no ensaio 6 houve a maior conversão de produto para a produção de leite em pó, em contrapartida nos ensaios 7 e 12 houve uma menor produção do produto. A conversão de produto durante o processamento do leite em pó seja ele de qualquer espécie é um indicador importante principalmente de lucratividade e determina a viabilidade econômica, embora o teor de sólidos do leite influencie diretamente no rendimento do leite em pó, o leite ovino possui um teor de sólidos superior que segundo Wendorff, (2002) pode variar entre 15,42 a 20,61\%.

Tabela 2. Matriz do DCCR $2^{3}$ para as respostas conversão, tempo e umidade.

\begin{tabular}{ccccccc}
\hline \multirow{2}{*}{ Ensaio } & \multicolumn{3}{c}{ Variáveis Independentes } & \multicolumn{3}{c}{ Variáveis Dependentes } \\
\cline { 2 - 7 } $\mathbf{1}$ & Pressão (bar) & Vazão $(\mathrm{L} / \mathrm{h})$ & Temp. $\left({ }^{\circ} \mathrm{C}\right)$ & Conversão $(\%)$ & Tempo $(\mathrm{h})$ & Umidade $(\%)$ \\
$\mathbf{2}$ & $-1(1,2)$ & $-1(3,5)$ & $-1(150)$ & $7,0 \%$ & $01: 45$ & 2,93 \\
$\mathbf{3}$ & $+1(1,8)$ & $-1(3,5)$ & $-1(150)$ & $9,0 \%$ & $01: 45$ & 3,75 \\
$\mathbf{4}$ & $-1(1,2)$ & $+1(4,9)$ & $-1(150)$ & $6,0 \%$ & $01: 25$ & 2,70 \\
$\mathbf{5}$ & $+1(1,8)$ & $+1(4,9)$ & $-1(150)$ & $6,5 \%$ & $01: 10$ & 3,78 \\
$\mathbf{6}$ & $-1(1,2)$ & $-1(3,5)$ & $+1(170)$ & $7,0 \%$ & $01: 32$ & 2,76 \\
$\mathbf{7}$ & $+1(1,8)$ & $-1(3,5)$ & $+1(170)$ & $11,0 \%$ & $01: 45$ & 1,22 \\
$\mathbf{8}$ & $-1(1,2)$ & $+1(4,9)$ & $+1(170)$ & $4,0 \%$ & $01: 20$ & 3,11 \\
$\mathbf{9}$ & $+1(1,8)$ & $+1(4,9)$ & $+1(170)$ & $8,0 \%$ & $01: 20$ & 1,85 \\
$\mathbf{1 0}$ & $0(1,6)$ & $0(4,2)$ & $0(160)$ & $5,5 \%$ & $01: 15$ & 4,18 \\
$\mathbf{1 1}$ & $0(1,6)$ & $0(4,2)$ & $0(160)$ & $5,5 \%$ & $01: 20$ & 4,21 \\
$\mathbf{1 2}$ & $0(1,6)$ & $0(4,2)$ & $0(160)$ & $5,0 \%$ & $01: 25$ & 4,18 \\
$\mathbf{1 3}$ & $-1,68(0,9)$ & $0(4,2)$ & $0(160)$ & $4,0 \%$ & $02: 04$ & 2,88 \\
$\mathbf{1 4}$ & $+1,68(1,9)$ & $0(4,2)$ & $0(160)$ & $9,0 \%$ & $01: 20$ & 4,53 \\
$\mathbf{1 5}$ & $0(1,6)$ & $-1,68(3,0)$ & $0(160)$ & $6,0 \%$ & $01: 51$ & 1,92 \\
$\mathbf{1 6}$ & $0(1,6)$ & $+1,68(5,4)$ & $0(160)$ & $8,0 \%$ & $01: 15$ & 1,72 \\
$\mathbf{1 7}$ & $0(1,6)$ & $0(4,2)$ & $-1,68(143)$ & $7,5 \%$ & $01: 30$ & 1,80 \\
\hline
\end{tabular}


A Figura 3 ilustra o gráfico de Pareto para os efeitos, este diagrama apresenta de forma rápida e clara o efeito que é estatisticamente importante, ou seja, significativo, no caso a pressão de alimentação (L) e (Q) cujo valor é maior que $\mathrm{p} \geq 0,05$. O valor do efeito linear para a pressão foi positivo e significativo no nível de confiança de $95 \%$, ou seja, está é a variável mais relevante para o processo. Isso comprova o fato de que, quanto maior a pressão de alimentação, maior será a conversão do leite em pó.

Guerra et. al., (2005), avaliou o processo de obtenção de leite em pó bubalino em secador por nebulização sendo que as melhores condições de secagem foram obtidas com as temperaturas do ar na entrada e saída do secador de $140^{\circ} \mathrm{C}$ e $75^{\circ} \mathrm{C}$, respectivamente. Nestas condições o produto final não sofreu escurecimento característico da reação de Maillard.

A Equação 2 apresenta o modelo codificado de segunda ordem, que descreve a conversão de pó em função das variáveis significativas analisadas (vazão e pressão), dentro das faixas estudadas. $\mathrm{O}$ modelo foi validado pela análise de variância onde obteve-se um coeficiente de correlação de 0,54 e o F calculado 4,13 valor este maior que o valor tabelado, o qual permitiu a validação do modelo e a construção das superfícies de resposta e/ou curva de contorno apresentadas na Figura 4 (a e b).

$$
\text { Rendimento }=0,345-0,142 \times \mathrm{P}+0,067 \times \mathrm{P}^{2}-0,094 \times \mathrm{V}+0,010 \mathrm{~V}^{2}
$$

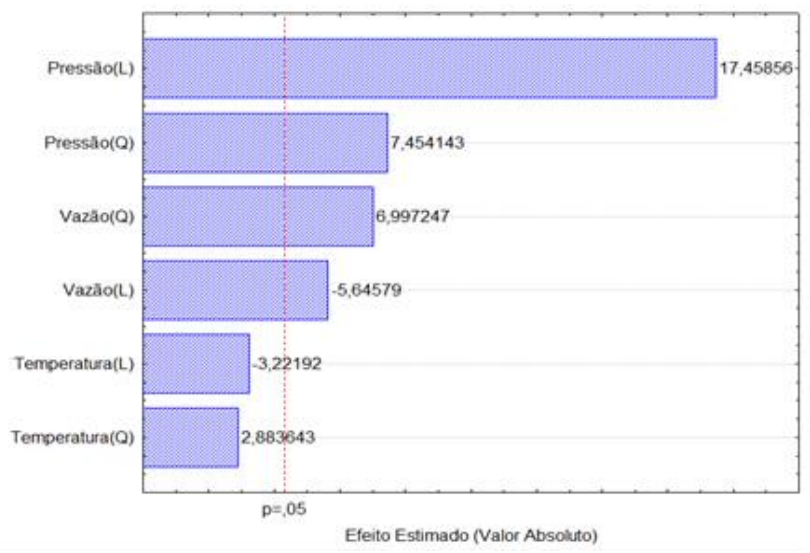

Figura 1. Diagrama de Pareto das variáveis testadas no DCCR 23, para a conversão do leite em pó.

Com relação ao tempo de processamento (Figura 5 a) podemos observar que as variáveis vazão e pressão foram significativas para o processo, ou seja, o efeito da variável vazão foi negativo o que na prática quer dizer que em valores menores deste parâmetro o processo terá melhores desempenhos. Já o efeito contrario é observado para a pressão, a qual poderia ser aumentada, mas cabe ressaltar que o equipamento utilizado durante a realização do experimento permite operar o mesmo apenas até 2 bar. $\mathrm{O}$ experimento 4 foi o que apresentou melhores resultados para esta variável, porém a vazão 
utilizada neste ensaio foi maior, o que acarreta na diminuição da conversão de produto, aumento da umidade e por consequiência de sua atividade de água, por isso o balanceamento correto desta variável é fundamental para a obtenção de um leite em pó de qualidade.

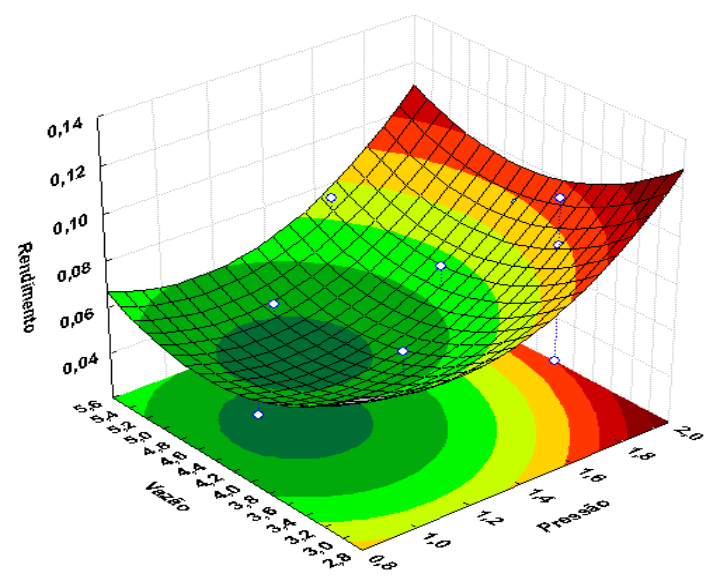

(a)

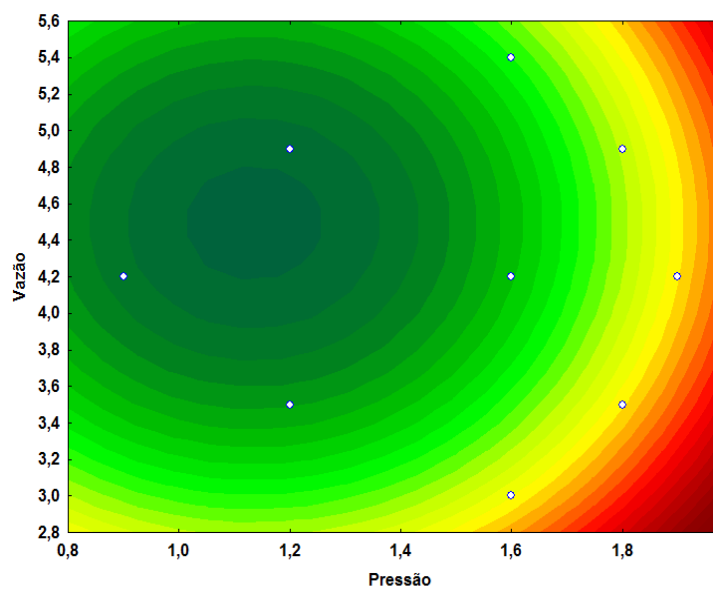

(b)

Figura 4. Superfícies de resposta (a) e curva de contorno (b) para a conversão do leite em pó em função da pressão e vazão de alimentação.

A análise estatística da variável tempo resultou em um modelo empírico codificado para a produção de leite em pó de ovelha. $\mathrm{O}$ modelo foi validado pela análise de variância. A análise apresentou um coeficiente de determinação de 0,74 , um alto valor do teste-F para a regressão.

A Equação 3 apresenta o modelo codificado de segunda ordem, que descreve o tempo em função das variáveis (Vazão e Pressão), dentro da faixa estudada. A validação do modelo permitiu a construção das superfícies de resposta e curva de contorno apresentadas na Figura 6 (a e b). O modelo empírico também foi validado, pois F-calculado maior que F-tabelado. O modelo empírico com as variáveis significativas está apresentado na Equação 3:

$$
\text { Tempo }=0,119-0,005 \times \mathrm{P}^{2}-0,011 \times \mathrm{V}
$$

Os dados analisados em termos da umidade (Figura 5 b) apresentam que vazão de alimentação quadrática, influencia significativamente na queda da umidade $(\mathrm{p}<0,05)$, sendo está de forma negativa para o processo de obtenção do leite em pó, ou seja, quanto menor a vazão melhor para a redução na umidade no produto final. 


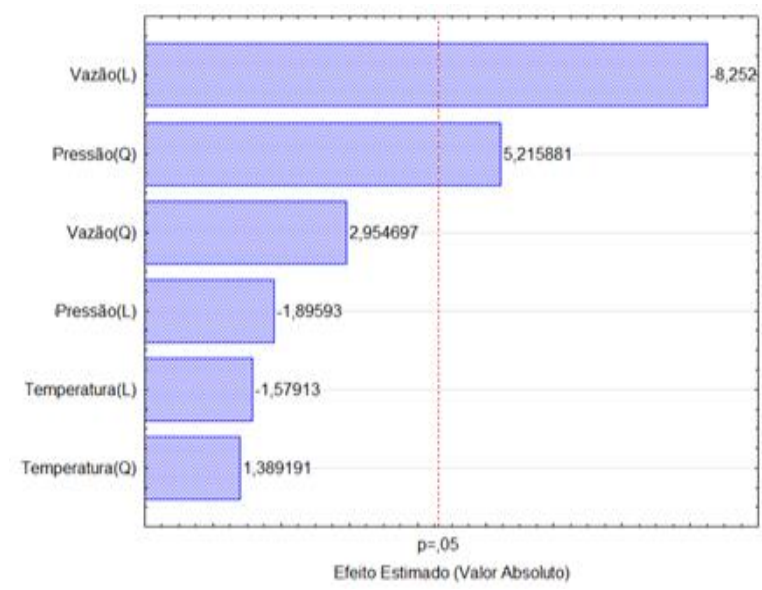

(a)



(b)

Figura 5. Diagrama de Pareto das variáveis testadas no DCCR $2^{3}$, para o tempo (a) e umidade (b) de processamento do leite em pó.

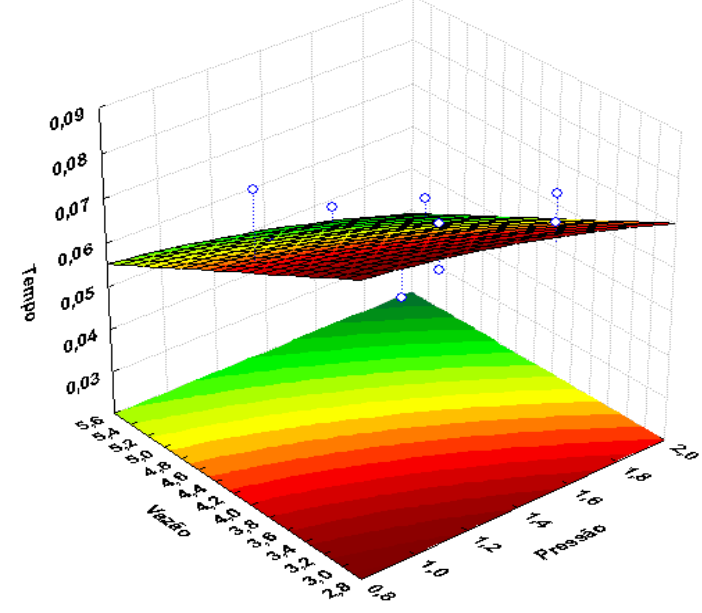

(a)

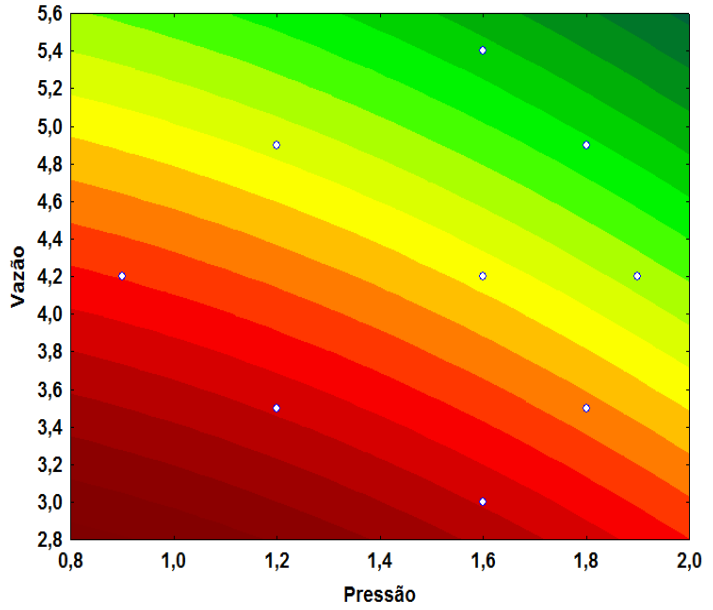

(b)

Figura 6. Superfície de resposta (a) e contorno (b) para a variável significativa "tempo de processamento" com $95 \%$ de significância.

Para a análise estatística referente o teor de umidade não foi possível a construção de um modelo empírico codificado para a produção de leite em pó de ovelha para este atributo, o modelo não foi validado pela análise de variância, onde o valor do teste-F calculado foi menor que o tabelado e com isso não foram geradas as superfícies de resposta e de contorno. 
O Regulamento Técnico de Identidade e Qualidade de Leite em Pó, pela portaria n ${ }^{\circ} 146$ do MAPA (BRASIL, 1996), estipula teor máximo de umidade para este produto em 3,5\%. Com relação a este parâmetro os ensaios 2, 4, 9, 10, 11 e 13 apresentaram umidade superior aos 3,5\% para o leite em pó integral.

\section{CONCLUSÃO}

O uso da técnica de planejamento experimental possibilitou a otimização do equipamento utilizado para a secagem do leite em pó onde a melhor condição do processo ocorreu em: $170^{\circ} \mathrm{C}$ de temperatura, vazão de alimentação de $3,5 \mathrm{~L} / \mathrm{h}$ e pressão de 1,8 Bar a conversão de produto obtido nestas condições de processamento foi de $11 \%$ e umidade $1,22 \%$.

\section{REFERÊNCIAS}

ASSENAT, L. Composición e propiedades. In: LUQUET, F.M. Leche y productos lácteos: vacaoveja-cabra. Zaragoza: Acribia, 1991. p.277-313.

GUERRA, R. B; NEVES E. C. A; PENA, R. S. Caracterização e processamento de leite bubalino em pó em secador por nebulização. Ciênc. Tecnol. Aliment., Campinas, 25(3): 443-447, jul.-set. 2005443

TORMEN, E. Leite em pó de ovelha. Rural Pecuária, 2011. Disponível em: http://www.ruralpecuaria.com.br/2011/04/leite-em-po-de-ovelha.html. Acesso em: 0312/2012.

WENDORFF, B. Milk composition and cheese yield. In: Great lakes dairy sheep symposium, 2002, Ithaca. Proc ... Ithaca: Cornell University, 2002. p. 104-117.

BRASIL. Ministério da Agricultura, do Abastecimento e da Reforma Agrária. Portaria $\mathrm{n}^{\circ}$ 146, de 07 de março de 1996. Aprova os Regulamentos Técnicos de Identidade e Qualidade dos Produtos Lácteos. Diário Oficial da República Federativa do Brasil, Brasília, 11 mar. 1996. 